\title{
Avaliação do ângulo nasolabial e do lábio superior em jovens tratados ortodonticamente com extrações de quatro pré-molares*
}

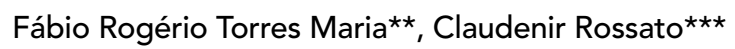

\begin{abstract}
Resumo
A previsibilidade das possíveis alterações do perfil facial tegumentar decorrentes do tratamento ortodôntico, em pacientes ainda susceptíveis a fatores de crescimento, parece ser bastante complexa, além de dependente de inúmeras variáveis. A partir disto, propôs-se avaliar 40 pacientes jovens ( 20 do gênero masculino e 20 do feminino), tratados ortodonticamente com extrações de 4 pré-molares, de acordo com os princípios da técnica preconizada por Tweed-Merrifield. Da amostra selecionada, 23 casos apresentavam má oclusão de Classe I e 17 apresentavam Classe II, divisão 1 de Angle, com idades médias no início do tratamento de 12,4 e 12,3 anos para o gênero feminino e masculino, respectivamente. Os resultados encontrados denotaram que o Ângulo Nasolabial (ANL) tornou-se mais obtuso com o tratamento $\left(6,11^{\circ}\right)$, provavelmente em decorrência da retração de seu componente labial que se seguiu à retração dos incisivos superiores. Quanto ao componente nasal, seu crescimento para frente e para baixo contribuiu para que este aumento não fosse ainda maior. Assim, as alterações ocorridas nos 2 componentes anatômicos do ANL (labial e nasal), provocaram, no seu conjunto, uma rotação no sentido horário. Quanto ao lábio superior, este apresentou um espessamento tanto em vermelhidão quanto na região do sulco labial superior, não sendo possível identificar sua verdadeira relação com o crescimento e/ou retração dos incisivos superiores. Quando as variáveis foram avaliadas quanto ao gênero, no masculino o ANL apresentou um menor aumento $\left(5,52^{\circ}\right)$, em virtude de um maior crescimento nasal para frente e para baixo, além de uma menor retração labial, a qual pode ter sido compensada por um maior espessamento do lábio superior. No feminino, o ANL apresentou um maior aumento $\left(7,20^{\circ}\right)$, com menor crescimento nasal e maior retração labial, que presumivelmente ocorreu em função de um insignificante aumento da espessura do lábio superior.
\end{abstract}

Palavras-chave: Ângulo nasolabial. Lábio superior. Tratamento com extrações.

* Trabalho apresentado à Universidade Estadual de Londrina para conclusão do Curso de Especialização em Ortodontia e Ortopedia Facial

** Mestre em Ortodontia, Professor da Universidade Paranaense (Unipar)

*** Doutor em Ortodontia, Professor Associado da Universidade Estadual de Londrina (UEL). 


\section{INTRODUÇÃO E REVISÃO DA LITERATURA}

A Ortodontia, em seus primeiros passos como uma especialidade odontológica, estabelecia como metas a serem alcançadas pelo tratamento, objetivos meramente estáticos, onde acreditava-se que um correto posicionamento dentário nos arcos garantiria, por si só, um equilíbrio e harmonia do perfil facial tegumentar. Além disso, a possibilidade da extração de dentes, para correções de discrepâncias dentoesqueléticas, não era sequer admitida, pois acreditava-se que uma mêcanica expansionista poderia estimular o crescimento das bases ósseas, acomodando, por conseguinte, todos os elementos dentários.

Este equívoco histórico passou a ser questionado algumas décadas depois por Tweed ${ }^{58}$, que auxiliado pela avaliação cefalométrica, passou a defender um correto posicionamento dos incisivos inferiores dentro de sua base apical, objetivo este que passaria muitas vezes pela necessidade de extrações dentárias, com conseqüente efeito direto sobre o posicionamento dos tecidos moles peribucais. Para Burstone ${ }^{11}$, a estética e função dos tecidos peribucais influem não somente na digestão, fonética e respiração, mas também exercem enorme influência na aceitação social e no bem estar psicológico do indivíduo. Deste modo, após anos de discussões e pesquisas, esta preocupação com o perfil facial e sua relação com o tratamento ortodôntico tornou-se fato consagrado e unânime.

A partir disto, procurou-se incessantemente o estabelecimento de padrões de previsibilidade, associando mudanças dentoesqueléticas subjacentes com possíveis alterações tegumentares que se seguiram a um determinado procedimento ortodôntico, ortopédico e/ou cirúrgico. Enquanto parece já estar clara uma interrelação genérica entre o perfil dentoesquelético e o tegumentar, outras variáveis tais como crescimento, idade, gênero, características étnicas, tônus/tensão labial, tecido adiposo, muscular e conjuntivo criam, em conjunto, uma vasta gama de opções que podem interferir, direta ou indiretamente, na relação tratamento/resposta labial, ratificando os argumentos de Ricketts ${ }^{47}$. Tomando como base o padrão facial, as alterações decorrentes do crescimento e o tratamento ortodôntico, Ricketts ${ }^{46}$ procurou demonstrar alguns procedimentos que pudessem prever possiveis resultados a serem obtidos. Em relação ao comportamento do perfil mole, ressaltou principalmente modificações na regiões dos lábios, nariz e mento mole. Sugeriu, para um maior equilíbrio labial, que projeções labiais acentuadas deveriam ser corrigidas através de modificações dentoesqueléticas subjacentes (retração dos incisivos), relação retração/resposta labial corroborada por

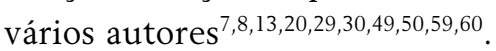

Para Subtelny e Rochester ${ }^{55}$, assim como Rudee $^{50}$ e Matsunaga ${ }^{40}$, áreas que se comportam com certa independência em relação ao tratamento, tais como o nariz e o mento, devem também ser levadas em consideração no diagnóstico, para que a mecânica empregada não potencialize possíveis tendências anti-estéticas de crescimento e maturação nestas áreas. Considerando a estreita relação entre a base do nariz e o lábio superior, a primeira referência à importância do ângulo nasolabial se deu em 1967, quando Burstone ${ }^{13}$ considerou bastante evidente a tendência de abertura deste ângulo a partir da retração dos incisivos superiores.

Depois de algum tempo, a partir do início da década de 80 , Elias $^{17}$ e outros ${ }^{6,9,15,16,18,23,35,57,59}$ também se dedicaram à reforçar a relevância da abertura deste ângulo quando da retração dos incisivos superiores. Além disso, vários estu$\operatorname{dos}^{14,19,39}$ procuraram enfatizar a importância de se avaliar o ângulo nasolabial não apenas em seu valor absoluto, mas principalmente em relação ao seu comportamento espacial, relacionandose separadamente os vetores labial e nasal com um plano de referência esquelético independente (plano de Frankfurt). 
Finalmente, outro ponto de suma importância diz respeito às preocupações com a técnica empregada, extrações ou não de dentes, além da quantidade de retração dos incisivos superiores. Dentre as várias filosofias de tratamento, há uma certa estigmatização que onera a técnica de Tweed-Merrifield como tendo um maior efeito sobre o perfil facial, tornando-o mais achatado (perfil Tweediano), fato este a ser também investigado no presente estudo.

\section{PROPOSIÇÃO}

A finalidade deste estudo foi averiguar a resposta do tecido tegumentar em pacientes jovens tratados ortodonticamente, utilizando-se os princípios da técnica preconizada por TweedMerrifield para casos com extrações de pré-molares.

Em função da retração dos incisivos superiores e do crescimento, propôs-se a avaliar:

a) O comportamento do ângulo nasolabial;

b) O comportamento do lábio superior e

c) A presença ou não de dimorfismo sexual na avaliação das variáveis estudadas.

\section{MATERIAL E MÉTODOS Material}

A amostra deste estudo, de caráter retrospectivo, foi composta por 40 pacientes jovens, sendo 23 destes pertencentes ao acervo do curso de Especialização em Ortodontia e Ortopedia Facial da Universidade Estadual de Londrina, e os outros 17 foram obtidos de duas clínicas particulares de Londrina, tendo como critério indispensável que todos os casos tivessem sido submetidos aos princípios de tratamento baseados na técnica preconizada por Tweed-Merrifield para casos com extrações de 4 pré-molares. Destes, 27 foram submetidos a extrações de 4 primeiros pré-molares, e 13 tiveram os segundos pré-molares inferiores extraídos. Vinte e três apresentavam má oclusão de Classe I de Angle e 17 má oclusão de Classe II de Angle, sendo 20 do gênero masculino e 20 do feminino, com idade média de 12,3 e 12,4 anos para os gêneros masculino e feminino, respectivamente. Em todos os casos foram utilizados ganchos "J" tanto para a retração de caninos como para controle de ancoragem. Além disso, a retração dos incisivos foi realizada com mecânica com alças verticais entre os incisivos laterais e os caninos. Adicionalmente, as extrações se basearam em critérios relacionados ao apinhamento inicial, características cefalométricas e do perfil facial tegumentar. A amostra total foi dividida quanto ao gênero em dois grupos de 20 pacientes, para verificação de um possivel dimorfismo sexual. As avaliações cefalométricas foram feitas em dois períodos distintos, pré e pós-tratamento, englobando 80 telerradiografias em norma lateral, com intervalo médio entre os dois traçados de 4,7 anos para o gênero masculino e de 4,9 anos para o feminino.

\section{Métodos}

\section{Elaboração do cefalograma}

Após a delimitação das estruturas anatômicas e dos pontos usualmente utilizados, todos obtidos manualmente (S-Sela; N-Násio; Pó-Pório; Or-Orbitário; ENP-Espinha nasal posterior; ENA-Espinha nasal anterior; Sn-Subnasal e Ls-Labrale superior), de acordo com Krogman e Sassouni ${ }^{34}$ (Fig.1), efetuou-se a localização de pontos cefalométricos específicos utilizados por Oliver ${ }^{43}$, com localização também manual.

- Ponto M - Ponto em tecido mole correspondente ao ponto A esquelético, construído geometricamente a partir da obtenção de uma bissetriz entre os pontos Subnasal e labrale superior. O cruzamento deste bissetor com o sulco do lábio superior define este ponto (Fig.1).

- Ponto U - Ponto mais anterior da convexidade do vermelhidão do lábio superior (Fig.2).

- Ponto Q - Ponto situado na borda incisal do incisivo central superior (Fig.2).

- Ponto J - Ponto de intersecção da linha paralela ao plano palatino, passando pelo ponto $\mathrm{M}$, com a linha vertical de referência posterior (esta linha será definida na seção Linhas e Planos) (Fig.2). 


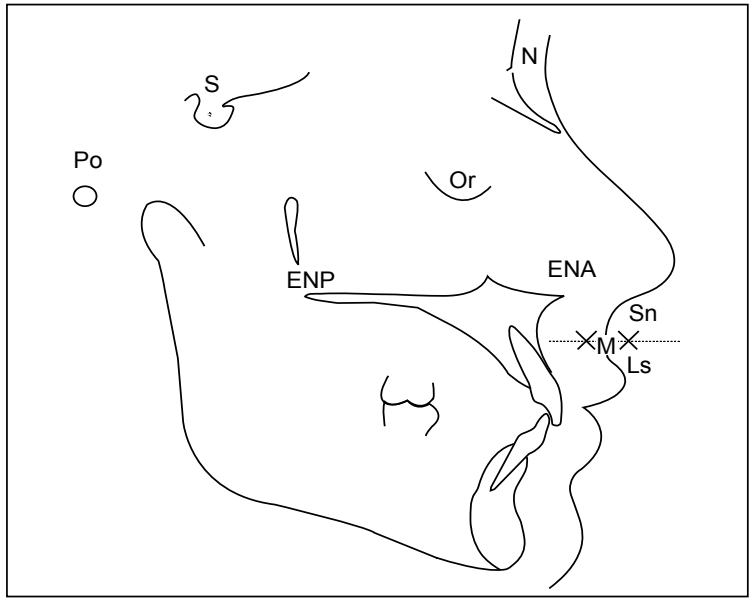

FIGURA 1 - Estruturas anatômicas e delimitação dos pontos cefalométricos (S, Po, Or, N, ENA, ENP, Sn e Ls) e do ponto $\mathrm{M}^{43}$.

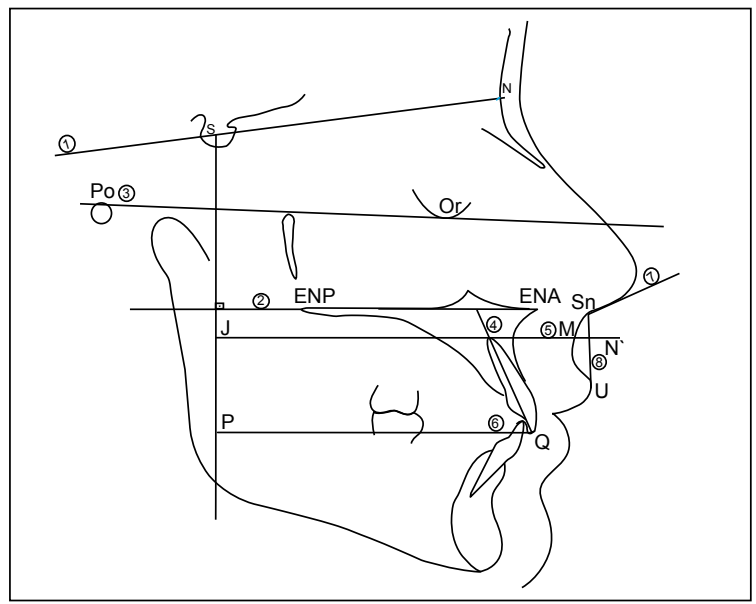

FIGURA 3 - Linhas e planos utilizados: 1) Linha Sn; 2) Plano palatino; 3) Plano de Francfort; 4) Linha do longo eixo do ICS; 5) Linha JN'; 6) Linha PQ; 7) Linha da base do nariz; 8) Linha do lábio superior (Sn-U).

- Ponto K - Ponto de intersecção da linha paralela ao plano palatino, passando pelo ponto $\mathrm{M}$, com a curvatura anterior anterior da maxila (correspondente ao ponto A) (Fig.2).

- Ponto T - Ponto de intersecção da linha paralela ao plano palatino, passando pelo ponto U, com a face vestibular do incisivo central superior (Fig.2).

- Ponto L - Projeção do ponto T sobre a linha paralela ao plano palatino, passando pelo ponto M (Fig.2).

- Ponto N' - Projeção do ponto U sobre a linha

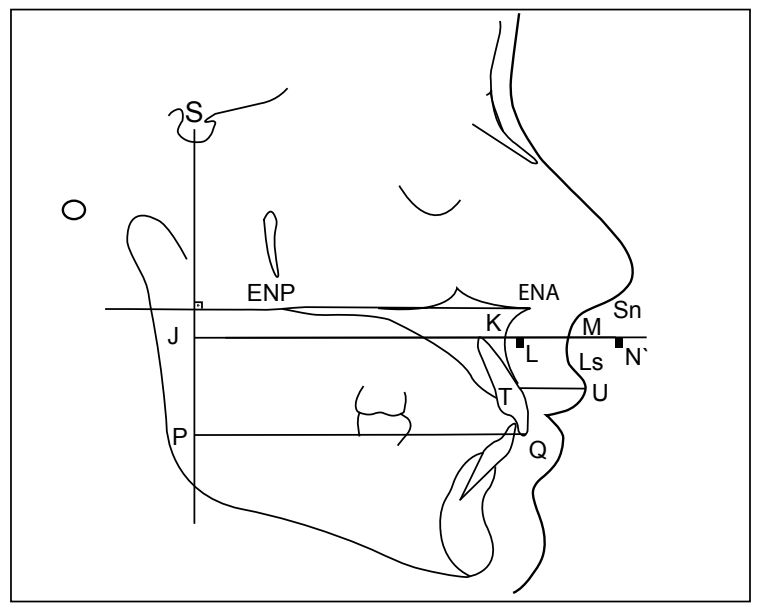

FIGURA 2 - Linhas de referência e medidas lineares ântero-posteriores (JK, JL,JM , JN', PQ, KM E TU)

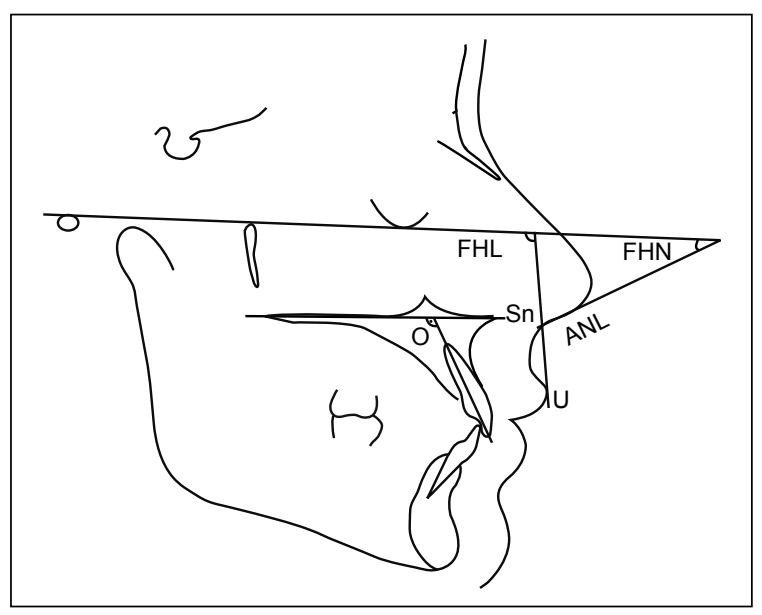

FIGURA 4 - Grandezas angulares (ANL,FHN,FHL e ângulo 0).

paralela ao plano palatino, passando pelo ponto M (foi utilizado N' para diferenciá-lo do ponto N correspondente ao Násio) (Fig.3).

- Ponto P - Intersecção da linha paralela ao plano palatino, passando pelo ponto $Q$ com a linha vertical de referência posterior (Fig.3).

\section{Linhas e planos utilizados}

Foram utilizados como referência horizontal, o plano de Frankfurt (Po-Or) e o plano palatino (ENA-ENP), sendo este último usado como referência entre os traçados pré e pós-tratamento. 
Para isto, no traçado correspondente ao período póstratamento, copiou-se o plano palatino do cefalograrma inicial, sobrepondo-se os dois cefalogramas na parede anterior da sela túrcica e mantendo-se a posição vertical da espinha nasal anterior pré-tratamento. Quanto às linhas, foram utilizadas a linha SN, a linha do longo eixo do incisivo central superior, a linha de referência vertical posterior (linha traçada perpendicularmente ao plano palatino passando pelo ponto S (Sela) , além da linha da base nasal, a qual tangencia a margem inferior da base do nariz passando pelo ponto Sn, e a linha do lábio superior, a qual tangencia o ponto mais anterior do vermelhidão do lábio superior (ponto $\mathrm{U}$ ), passando pelo ponto $\mathrm{Sn}$.

\section{Grandezas lineares}

Dentre as grandezas lineares utilizadas neste estudo ( JK, JL, JM, JN',PQ,KM e TU) vistas na figura 2, destacam-se as medidas KM (medida linear entre os pontos $\mathrm{K}$ e $\mathrm{M}$, correspondente à espessura da base do lábio superior) e a medida TU (medida linear entre os pontos $\mathrm{T}$ e $\mathrm{U}$, correspondente à espessura do lábio superior, expressa entre a superfície vestibular do incisivo central superior até a borda mais anterior do vermelhidão do lábio superior). A medida da tensão labial foi efetuada através da diferença entre as medidas KM e TU, como preconizado por Holdaway ${ }^{27}$. Quanto às demais medidas lineares, JK corresponde à posição anterior da maxila em relação à linha de referência vertical posterior; JL corresponde à distância da face vestibular do incisivo central superior em relação à mesma linha; JM e JN'correspondem respectivamente à posição da base do lábio superior e do lábio superior em vermelhidão em relação à mesma linha posterior. Finalmente, PQ se refere à distância linear da borda incisal do incisivo central superior em relação à referência posterior, podendo caracterizar alterações de torque e/ou retroinclinação destes incisivos.

\section{Grandezas angulares}

- ANL (ângulo nasolabial): Medida angular da relação da base do nariz com o lábio superior (borda inferior do nariz-Sn-ponto U);

- FHN (ângulo naso-Frankfurt): Medida angular do componente nasal do ANL(Sn-borda inferior do nariz) com o plano de Frankfurt;

- FHL (ângulo lábio-Frankfurt): Medida angular do componente labial do ANL (Sn-ponto U) com o plano de Frankfurt e;

- Ângulo O - Medida angular da inclinação do longo eixo do incisivo central superior com o plano palatino.

\section{Método estatístico}

Os valores individuais foram utilizados para as determinações estatísticas subseqüentes, incluindo o cálculo das médias aritméticas e dos desvios-padrão apresentados nas tabelas, para cada uma das variáveis estudadas na amostra. Além disto, empregou-se o teste " $t$ " de Student pareado, ao nível de $5 \%$, com o intuito de avaliar a significância estatística das alterações ocorridas durante os períodos de crescimento e tratamento considerados, nas 11 variáveis investigadas (quatro angulares e sete lineares), assim como detectar um possível dimorfismo sexual associado com as características do perfil facial tegumentar. Além disso, 8 pacientes foram escolhidos aleatoriamente, e tiveram seus traçados cefalométricos pré e pós-tratamento refeitos manualmente com intervalo de 15 dias, para verificação de um possível erro do método intra-examinador, sendo os valores da primeira e segunda mensurações submetidos ao teste " $t$ " de Student pareado, ao nível de 5\%, não tendo sido observados diferenças estatisticamente significantes entre as duas medições.

\section{RESULTADOS}

As tabelas 1, 2, 3 e 4 apresentam os resultados aferidos para a amostra total, juntamente com as amostras divididas quanto ao gênero. A tabela 1 apresenta valores das médias aritméticas e desvios-padrão das medidas cefalométricas angulares (em graus) pré e pós-tratamento, 


\begin{tabular}{|c|c|c|c|c|c|c|c|c|c|c|c|c|}
\hline \multirow{3}{*}{ Variável } & \multicolumn{6}{|c|}{ Pré-Tratamento } & \multicolumn{6}{|c|}{ Pós-Tratamento } \\
\hline & \multicolumn{2}{|c|}{ Total } & \multicolumn{2}{|c|}{ Masculino } & \multicolumn{2}{|c|}{ Feminino } & \multicolumn{2}{|c|}{ Total } & \multicolumn{2}{|c|}{ Masculino } & \multicolumn{2}{|c|}{ Feminino } \\
\hline & Média & DP & Média & DP & Média & DP & Média & DP & Média & DP & Média & DP \\
\hline ANL & 102,45 & 10,82 & 101,80 & 10,26 & 102,60 & 11,85 & 108,56 & 9,32 & 107,32 & 10,60 & 109,80 & 7,92 \\
\hline FHN & 24,46 & 6,55 & 25,48 & 6,40 & 23,42 & 6,71 & 20,70 & 6,49 & 21,15 & 7,37 & 20,25 & 5,64 \\
\hline FHL & 102,19 & 8,98 & 102,95 & 7,71 & 101,37 & 10,24 & 92,55 & 7,78 & 94,45 & 7,94 & 90,70 & 7,32 \\
\hline ANG.0 & 110,31 & 5,97 & 111,85 & 6,53 & 108,78 & 5,04 & 106,86 & 6,31 & 109,35 & 5,50 & 104,37 & 6,21 \\
\hline
\end{tabular}

Tabela 2 - Diferenças médias, desvios padrão e teste " $\mathrm{t}$ " de Student, das medidas cefalométricas angulares (em graus) da amostra total $(n=40)$ e das amostras do gênero masculino $(n=20)$ e feminino $(n=20)$.

\begin{tabular}{|c|c|c|c|c|c|c|c|c|c|}
\hline \multirow{2}{*}{ Variável } & \multicolumn{3}{|c|}{ Total } & \multicolumn{3}{|c|}{ Masculino } & \multicolumn{3}{|c|}{ Feminino } \\
\hline & Dif. média & DP & "t" & Dif. média & DP & "t" & Dif. média & DP & "t" \\
\hline ANL & $+6,11$ & 8,8 & $4,40^{*}$ & $+5,52$ & 7,73 & $3,00^{*}$ & $+7,20$ & 9,07 & $3,22^{*}$ \\
\hline FHN & $-3,76$ & 6,19 & $3,93^{*}$ & $-4,33$ & 7,08 & $2,84^{*}$ & $-3,17$ & 5,31 & $2,70^{*}$ \\
\hline FHL & $-9,63$ & 7,35 & $8,38^{*}$ & $-8,55$ & 6,13 & $6,35^{*}$ & $-10,4$ & 8,35 & $5,73^{*}$ \\
\hline ANG.0 & $-3,45$ & 6,73 & $2,94^{*}$ & $-2,5$ & 6,75 & $1,46 \mathrm{~ns}$ & -4.4 & 6,83 & $2,72^{*}$ \\
\hline
\end{tabular}

${ }^{*}$ Significante para $p<0,05(\mathrm{t}$ crítico $=1,68)$, ns $=$ não significante.

\begin{tabular}{|c|c|c|c|c|c|c|c|c|c|c|c|c|}
\hline \multirow{3}{*}{ Variável } & \multicolumn{6}{|c|}{ Pré-Tratamento } & \multicolumn{6}{|c|}{ Pós-Tratamento } \\
\hline & \multicolumn{2}{|c|}{ Total } & \multicolumn{2}{|c|}{ Masculino } & \multicolumn{2}{|c|}{ Feminino } & \multicolumn{2}{|c|}{ Total } & \multicolumn{2}{|c|}{ Masculino } & \multicolumn{2}{|c|}{ Feminino } \\
\hline & Média & DP & Média & DP & Média & DP & Média & DP & Média & DP & Média & DP \\
\hline TU & 14,36 & 2,30 & 15,13 & 2,28 & 13,58 & 2,14 & 15,99 & 3,10 & 18,15 & 2,57 & 13,95 & 2,08 \\
\hline KM & 14,20 & 1,90 & 15,13 & 1,63 & 13,33 & 1,69 & 15,65 & 2,32 & 17,48 & 1,37 & 13,83 & 1,43 \\
\hline JK & 68,05 & 6,19 & 71,03 & 5,80 & 65,07 & 5,14 & 70,62 & 7,10 & 75,72 & 5,35 & 65,55 & 4,50 \\
\hline $\mathrm{JL}$ & 71,50 & 6,80 & 74,80 & 6,58 & 68,20 & 5,36 & 73,21 & 7,88 & 78,75 & 6,00 & 67,68 & 5,18 \\
\hline JM & 2,25 & 7,13 & 86,07 & 6,52 & 78,43 & 5,57 & 86,19 & 8,71 & 93,18 & 5,49 & 79,20 & 4,76 \\
\hline $\mathrm{JN}$ & 86,18 & 7,68 & 90,35 & 7,39 & 82,00 & 5,26 & 89,20 & 9,34 & 96,65 & 5,76 & 81,75 & 5,40 \\
\hline $\mathrm{PO}$ & 71,74 & 7,28 & 75,40 & 7,40 & 68,07 & 5,08 & 72,31 & 8,59 & 78,37 & 6,43 & 66,25 & 5,73 \\
\hline
\end{tabular}




\begin{tabular}{|c|c|c|c|c|c|c|c|c|c|}
\hline \multirow{2}{*}{ Variável } & \multicolumn{3}{|c|}{ Total } & \multicolumn{3}{|c|}{ Masculino } & \multicolumn{3}{|c|}{ Feminino } \\
\hline & Média & DP & "t" & Média & DP & "t" & Média & DP & "t" \\
\hline TU & $+1,63$ & 2,81 & $4,18^{*}$ & $+3,02$ & 2,44 & $5,50^{*}$ & $+0,38$ & 1,91 & $0,86 \mathrm{~ns}$ \\
\hline KM & $+1,45$ & 1,66 & $5,74^{*}$ & $+2,36$ & 4,18 & $7,24^{*}$ & $+0,58$ & 1,12 & $2,15^{*}$ \\
\hline JK & $+2,57$ & 4,06 & $4,04^{*}$ & $+4,69$ & 5,1 & $5,03^{*}$ & $+0,48$ & 2,69 & $0,75 \mathrm{~ns}$ \\
\hline $\mathrm{JL}$ & $+1,71$ & 4,68 & $2,30^{*}$ & $+3,95$ & 5,04 & $3,51^{*}$ & $-0,52$ & 3,11 & $0,76 \mathrm{~ns}$ \\
\hline JM & $+3,94$ & 4,73 & $4,75^{*}$ & $+7,1$ & 4,39 & $6,44^{*}$ & $+0,77$ & 3,23 & $1,06 \mathrm{~ns}$ \\
\hline JN & $+3,03$ & 3,36 & $3,42^{*}$ & $+6,3$ & 4,99 & $5,65^{*}$ & $-0,25$ & 4,12 & $0,27 \mathrm{~ns}$ \\
\hline $\mathrm{PO}$ & $+0,58$ & 5,99 & $0,65 \mathrm{~ns}$ & $+2,97$ & 7,02 & $2,19^{*}$ & $-1,82$ & 3,83 & $2,13^{*}$ \\
\hline
\end{tabular}

* Significante para $p<0,05$ (t crítico $=1,68$ ), ns = não significante.

da amostra total $(n=40)$, assim como das amostras do gênero masculino $(n=20)$ e do feminino $(\mathrm{n}=20)$. A tabela 2 apresenta as diferenças médias, desvios-padrão e teste " $t$ " de Student, das medidas cefalométricas angulares (em graus) da amostra total $(\mathrm{n}=40)$, assim como das amostras divididas quanto ao gênero. A tabela 3 apresenta as médias aritméticas e desvios-padrão das medidas lineares (em milímetros) pré e pós-tratamento, da amostra total e das amostras divididas quanto ao gênero. Por fim, a tabela 4 apresenta as diferenças médias, desvios-padrão e teste " $\mathrm{t}$ " de Student, das medidas lineares (em milímetros) da amostra total e também das duas amostras divididas de acordo com o gênero.

\section{DISCUSSÃO}

A preocupação com as características do perfil facial esquelético e tegumentar, e seu interrelacionamento com o tratamento ortodôntico, faz parte há muitas décadas dos principais objetivos a serem considerados em um plano de tratamento $7,10,21,25,26,46,53,58$. Porém, a previsibilidade dos resultados do tratamento dentoesquelético sobre a face, contudo, é bem mais difícil e complexa. Para Ricketts ${ }^{46}$, esta predição passa necessariamente pela análise de variáveis relacionadas ao padrão facial e ao potencial quantitativo e qualitativo de cresci- mento $7,11,12,18,22,50,51,52,55,56$, além de outras variáveis a serem consideradas, tais como: características intrínsecas dos lábios (tecido adiposo, muscular, conjuntivo) $3,5,7,24,42$; etnia, gênero e idade $^{12,32,36,45,47,52}$; distância intercaninos ${ }^{3,24}$, além da espessura e tônus do lábio $1,2,10,29,33,38,40,41,43,46$. Em conjunto, esta gama de variáveis torna bastante difícil uma predição direta de possíveis respostas a serem esperadas ${ }^{5,13,20,33,38,43,49-51,60}$, principalmente pela observação de determinadas áreas do tecido tegumentar que parecem se comportar com certa independência dos tecidos duros subjacentes ${ }^{13,19,30,42,55,56}$. Neste estudo procurou-se avaliar o comportamento do ângulo nasolabial e sua relação com o tratamento ortodôntico em pacientes submetidos à técnica preconizada por Tweed-Merrifield, com extrações de pré-molares baseadas em critérios cefalométricos, de discrepâncias de modelo e das condições iniciais do perfil facial, e que ainda apresentavam potencial de crescimento. Desta forma não foi possível diferenciar alterações terapêuticas das alterações provocadas por crescimento, embora o que se tenha objetivado foi a análise das modificações do perfil facial, nesta faixa etária, quando os princípios da técnica em questão forem empregados. Embora haja um certo estigma que correlaciona estes princípios terapêuticos com um achatamento do perfil, 
o que se observou foram alterações com valores médios próximos a vários trabalhos que enfocaram as modificações do perfil facial correlacionadas a outras condutas mecânicas. $\mathrm{O}$ valor médio pré-tratamento para a amostra total do ANL foi de $102,45^{\circ}(\mathrm{dp}=10,26)$, com um valor pós-tratamento de $108,56^{\circ}(\mathrm{d} p=10,60)$, apresentando um aumento médio deste ângulo de $6,11^{\circ}$ (aumento de $5,52^{\circ}$ para o gênero masculino e de $7,20^{\circ}$ para o feminino). Estes valores médios se aproximaram dos achados por Lo e Hunter $^{37}$ (média de $104,33^{\circ}$ aos nove anos e $105,7^{\circ}$ aos 16 anos de idade), $97,8^{\circ}\left(90\right.$ a $\left.110^{\circ}\right)$ encontrados por Elias ${ }^{17}$, além dos auferidos por Magni e Di Blasio ${ }^{39}\left(109,1^{\circ}\right.$ para respiradores nasais e $108,1^{\circ}$ para respiradores buconasais). Contudo diferiram um pouco dos apresentados por Waldman ${ }^{59}\left(113^{\circ}\right)$ e Fitzgerald, Nanda e Currier ${ }^{19}\left(114^{\circ}\right.$, com $\left.\mathrm{dp}=10^{\circ}\right)$, além de serem bastante contrastantes com os valores atestados por Burstone ${ }^{13}$ (média de $73,8^{\circ}$, variando entre 60 e $90^{\circ}$ ), o qual considera este ângulo de suma importância para a avaliação do grau de protrusão do lábio superior com o nariz.

Embora o presente estudo não tenha medido o grau de retração dos incisivos superiores, ficou evidente que o ANL se tornou mais obtuso com o tratamento (aumento de $6,11^{\circ}$ ), fato unânime encontrado na literatura pertinente. M.F. Talass, L. Talasss e Baker ${ }^{57}$ verificaram um aumento de $0,8^{\circ}$ para cada $1 \mathrm{~mm}$ de retração incisal, tendo uma razão de abertura ainda maior em pacientes apresentando lábios finos. Lo e Hunter ${ }^{37}$ encontraram uma razão de $1,68^{\circ}: 1 \mathrm{~mm}$ de retração, sendo $90 \%$ desta relação concernente à retração incisal e os $10 \%$ restantes devidos a alterações do nariz. Outros, constataram aumentos diferenciados do ANL com o tratamento: Drobocky e $S$ mith ${ }^{16}$ encontraram valores bem próximos dos obtidos no presente estudo $\left(5,2^{\circ}\right)$; Lew $^{35}$ encontrou $10^{\circ}$; Battage $^{6}$ verificou $7,5^{\circ}$ para casos tratados com Ortodontia fixa e $2,9^{\circ}$ para casos tratados com aparelhos ortopédicos; Chimenti et al. ${ }^{14}$ encontraram $5^{\circ}$ para casos tratados com aparelho extrabucal com tração alta e $8,5^{\circ}$ para casos tratados com tração occipital e Bravo observou um aumento de $3,7^{\circ}$. Um maior aumento para o gênero feminino foi também atestado por Cummins, Bishara e Jakobsen ${ }^{15}$, enquanto outros $^{6,9,15,18,23,60}$ verificaram um maior aumento para casos tratados com extrações de dentes, quando comparados a tratamentos sem extrações.

Considerando-se possíveis riscos do achatamento do lábio superior decorrentes da retração dos incisivos, Robinson, Rinchuse e Zullo ${ }^{48}$ e Elias ${ }^{17}$ correlacionaram menores valores $\mathrm{d}$ o ANL a indivíduos apresentando uma maior convexidade esquelética, enquanto Waldman ${ }^{59}$ alerta para uma maior influência da retração incisal em casos apresentando uma maior inclinação do plano palatino. Finalmente, Phelps $^{44}$ acredita que apesar do ANL se abrir no sentido horário, o contorno do lábio superior é mantido por intermédio de um aumento na sua espessura. Considerando-se que o ângulo nasolabial possa ser influenciado pela retração dos incisivos, e também por alterações de crescimento e direcionamento do nariz, algumas considerações a este respeito devem ser discutidas. Para Subtelny e Rochester ${ }^{55}$, o crescimento nasal para frente e para baixo (com o componente vertical mais representativo) tem enorme importância sobre o ANL. Vários autores ${ }^{2,8,33,50,56}$ também evidenciaram a influência do crescimento nasal sobre o perfil, embora ressaltem grande difilculdade na predição de seu comportamento. Para Rezende e Martins ${ }^{45}$, deve-se ter bastante cautela quando da retração dos incisivos em virtude do seu impacto sobre os lábios, principalmente em casos apresentando condições nasais proeminentes e anti-estéticas.

Devido a esta influência nasal sobre o ANL, procurou-se neste estudo, avaliar separadamente os componentes nasal e labial deste ângulo, em relação a uma referência esquelética (plano de 
Frankfurt). Esta conduta foi baseada em procedimentos semelhantes conduzidos por Lo, Hunter $^{37}$; Heath ${ }^{23}$ e Chimenti et al. ${ }^{14}$, que acreditam que muitas vezes o valor absoluto do ANL não se altera durante as fases de crescimento e tratamento, podendo porém sofrer drásticas modificações espaciais (rotação de todo o ângulo no sentido horário, principalmente pelo abaixamento do componente nasal, pelo crescimento para frente e para baixo deste, e pelo retroposicionamento do componente labial, devido à retração dos incisivos ou correção de seu torque). Neste estudo, o componente angular nasal do ANL, denominado por Chimenti et al. ${ }^{14}$ de FHN (Frankfurt Horizontal Nasal), demonstrou para a amostra total, um valor médio pré-tratamento de $24,46^{\circ}$ $\left(\mathrm{d} p=6,40^{\circ}\right)$ e um valor médio pós-tratamento de $20,70^{\circ}\left(\mathrm{d} p=7,37^{\circ}\right)$, apresentando uma diminuição média deste ângulo na ordem de $-3,76^{\circ}\left(-4,33^{\circ}\right.$ para o gênero masculino e $-3,17^{\circ}$ para o gênero feminino). Esta diminuição do $\mathrm{FHN}$, maior para o grupo do gênero masculino, parece evidenciar um maior crescimento do nariz para frente e para baixo, influenciando assim o valor do ANL. O componente labial do ANL, também denominado por Chimenti et al. ${ }^{14}$ de FHL (Frankfurt Horizontal Labial), teve um valor médio para a amostra total no período pré-tratamento de $102,19^{\circ}$ $\left(\mathrm{d} p=7,71^{\circ}\right)$, seguido de um valor pós-tratamento de $92,55^{\circ}(\mathrm{dp}=7,94)$. Estes valores são bastante semelhantes aos achados por Fitzgerald, Nanda e Currier ${ }^{19}$, com um valor de $98,5^{\circ}$ e desvio-padrão de $5^{\circ}$. A diminuição deste ângulo entre as duas fases observadas, que em média foi de $-9,63^{\circ}$ para o grupo total $\left(-8,55^{\circ}\right.$ para o gênero masculino e $-10,40^{\circ}$ para o feminino), parece ser claro que se deve a um retroposicionamento labial devido à retração e correção do torque dos incisivos superiores, idéia corroborada também por Chimenti et al. ${ }^{14}$ e Waldman ${ }^{59}$.

O ângulo $O$, usado para avaliar a posição do incisivo central superior em relação ao plano palatino, apresentou valor médio para a amostra total de $110,31^{\circ}\left(\mathrm{dp}=6,53^{\circ}\right)$ no período pré-tratamento e $106,86^{\circ}\left(\mathrm{dp}=5,50^{\circ}\right)$ no período póstratamento, valores estes muito próximos aos encontrados por Oliver ${ }^{43}$. A diminuição média deste ângulo para a amostra total foi de $-3,45^{\circ}$ $\left(-2,50^{\circ}\right.$ para o grupo masculino e $-4,40^{\circ}$ para o feminino, embora os resultados do grupo masculino não tenham sido estatisticamente significantes). A diminuição deste ângulo, parece estar associada basicamente à correção do torque dos incisivos centrais superiores, maior neste estudo para o gênero feminino, podendo assim ter influência na postura do lábio superior e no ANL $^{14,59}$.

Além desta variabilidade de acompanhamento dos lábios à retração, bastante descrita na literatura, variações em sua espessura e em seu tônus também estão associadas a fatores inerentes ao tratamento e ao crescimento. Neste estudo, a espessura básica do lábio, avaliada pela medida KM, demonstrou um valor médio pré-tratamento para a amostra total de $14,20 \mathrm{~mm}(\mathrm{dp}=1,90)$ e de $15,65 \mathrm{~mm}$ na avaliação pós-tratamento. Na média, as espessuras da base do lábio se apresentaram maiores para o grupo masculino, o qual também apresentou um maior espessamento no período analisado, com aumento médio de $+2,36 \mathrm{~mm}$ (contra $+1,45 \mathrm{~mm}$ da amostra total e $+0,58 \mathrm{~mm}$ para o grupo feminino). Em relação à espessura do lábio superior na região do vermelhidão, avaliada pela medida $\mathrm{TU}$, os valores médios pré e pós-tratamento, para a amostra total, foram de $14,36 \mathrm{~mm}(\mathrm{dp}=2,3 \mathrm{~mm})$ e $15,99 \mathrm{~mm}(\mathrm{dp}=3,1 \mathrm{~mm})$, respectivamente, com aumento médio de espessura no período analisado de $+1,63 \mathrm{~mm}(+3,02 \mathrm{~mm}$ para o gênero masculino e apenas $+0,38 \mathrm{~mm}$ para o feminino, valor este não estatisticamente significante). Os valores da espessura labial se mostraram, em média, maiores para o gênero masculino, acordando com os achados de Burstone ${ }^{12}$. Com relação ao aumento da espessura labial, ficam intrincados fatores pertinentes ao tratamento, com a retração dos incisivos, e também referentes ao crescimento. Este fato acorda com Sain ${ }^{51}$, que atesta haver um 
aumento da espessura labial com o crescimento e com o tratamento baseado em extrações e retração de incisivos. Nesta mesma linha de raciocínio, Assunção et al. ${ }^{4}$; Huggins, Mcbride ${ }^{29}$ e Oliver ${ }^{43}$ afirmam que as respostas labiais ao tratamento são mascaradas por fatores associados ao crescimento. Neste estudo, o espessamento encontrado concorda com vários outros achados $2,18,28,33,38,40,45,57$, embora também não diferenciem efeitos de crescimento com os efeitos do tratamento. Considerando-se uma possível presença de tensão labial na região de vermelhidão, seja por excesso de protrusão dos incisivos, ou pelo excesso de altura vertical ânteroinferior, vários autores $1,5,10,13,27,31,33,41,43,54,56$ registram seus achados e associam sua redução ao retroposicionamento dos incisivos superiores. No presente estudo, com critérios usados primeiramente por Holdaway $^{27}$, esta possível tensão avaliada através da subtração dos valores da espessura da base do lábio superior (KM) com os valores da espessura do lábio superior em vermelhidão (TU), não foi constatada.

As medidas lineares relacionadas ao posicionamento da maxila em relação à base do crânio $(\mathrm{JK})$, demonstram um aumento médio ânteroposterior para o grupo do gênero masculino de 4,69mm (enquanto não apresentou-se significativo para o gênero feminino), demonstrando uma maior influência dos fatores de crescimento sobre esta região neste grupo. No confronto com outras medidas lineares (JL, JM e JN), seus incrementos lineares maiores e estatisticamente significantes (grupo masculino), confirmam a grande influência do crescimento nesta região naso-maxilar para este subgrupo, mascarando muitas vezes as alterações provocadas pelo tratamento ${ }^{4,29,43}$.

Na última medida linear considerada (PQ), que busca demonstrar a relação da borda incisal do incisivo central superior com a base do crânio, as diferenças médias encontradas para a amostra total não se mostraram estatisticamente significantes. No grupo masculino, esta medida demonstrou um aumento médio de $+2,97 \mathrm{~mm}$, reforçando dados lineares anteriores, onde o crescimento ântero-pos- terior da maxila mascarou possíveis movimentações para trás dos incisivos, seja por retração ou por ajuste de seu torque. Já no grupo feminino, o valor médio encontrado foi de $-1,82 \mathrm{~mm}$, demonstrando um retroposicionamento da borda incisal do incisivo central superior, seja por torque ou retração, fato este que pode ser reforçado por uma maior diminuição do ângulo $\mathrm{O}$, uma maior diminuição do ângulo FHL, além de uma menor influência do crescimento no complexo lábio-maxilar para este grupo, não mascarando assim os efeitos da mecânica empregada.

Com base no que foi discutido, tomando como referência os resultados obtidos no presente estudo e o confronto com os da literatura compulsada, fica evidente a relação existente entre o perfil tegumentar e as estruturas dentoesqueléticas subjacentes, principalmente em relação à retração dos incisivos superiores e de seu efeito sobre a abertura do ângulo nasolabial. Além disto, constatou-se uma rotação horária do ANL, em função da retração de seu componente labial (resultante do tratamento) e abaixamento de seu componente nasal (resultante do crescimento). Adicionalmente, não se confirmou a suposta tendência de achatamento de perfil relacionada a esta técnica, fortalecendo o conceito que os critérios relacionados a decisões de extrações e de quantidade de retração de incisivos é mais importante para o resultado final que o método terapêutico escolhido para atingí-lo. Entretanto, em virtude das limitações impostas pela amostra utilizada e a influência do crescimento no período avaliado, novas pesquisas que levem em consideração esta e outras variáveis são essenciais, para que resultados mais consistentes possam ser obtidos no que se refere à influência do tratamento ortodôntico sobre o perfil facial tegumentar.

\section{CONCLUSÕES}

Com base nos resultados obtidos entre as duas fases estudadas, pode-se concluir que: o ângulo nasolabial tornou-se mais obtuso em razão de um aumento de $6,11^{\circ}$, provavelmente em 
decorrência da retração do seu componente labial, que se seguiu à retração dos incisivos superiores; teve seu valor final influenciado pelo efeito do crescimento sobre seu componente nasal, para frente e para baixo, o que contribuiu para que este aumento não fosse ainda maior, e em função das alterações ocorridas nos seus dois componentes anatômicos (nasal e labial), denotou no seu conjunto uma rotação no sentido horário.

Quanto ao lábio superior, este apresentou um espessamento de $1,63 \mathrm{~mm}$ na região do vermelhidão e de $1,45 \mathrm{~mm}$ na região do sulco labial, não foi possível detectar se este espessamento ocorreu devido ao crescimento e/ou retração dos incisivos superiores e não encontrou-se presença de tensão labial, não exercendo portanto, nenhuma influência nos resultados concernentes à sua espessura.

Quando o ângulo nasolabial e o lábio superior foram avaliados separadamente quanto ao gênero, observou-se que, no masculino, o ANL apresentou um menor aumento $\left(5,52^{\circ}\right)$, devido a um maior crescimento para frente e para baixo do seu componente nasal e uma menor retração do lábio superior, que por sua vez, provavelmente tenha sido compensada por um maior efeito do crescimento sobre sua espessura $(+3,02 \mathrm{~mm})$. No feminino, o ANL apresentou um maior aumento $\left(7,20^{\circ}\right)$, devido a um menor crescimento no sentido horário do seu componente nasal e a uma maior retração do lábio superior, que por sua vez, presumivelmente, tenha ocorrido em razão do insignificante efeito do crescimento sobre sua espessura $(+0,38 \mathrm{~mm})$.

\title{
Nasolabial angle and upper lip evaluation in young patients treated orthodontically with four bicuspid extractions
}

\begin{abstract}
The predictability of possible soft-tissue profile changes concurrent to orthodontic treatment, in patients susceptible to growth factors, seems to be very complex besides dependent of several variables. From this, the purpose was to evaluate 40 young patients (20 males and 20 females) treated orthodontically with four bicuspid extractions according to Tweed-Merrifield principles technique. From the selected sample, 23 cases were Class I and 17 were Class II division 1, with average ages 12,4 and 12,3 years old for the males and females, respectively. The results denoted that nasolabial angle (ANL) measurement became more obtuse with treatment $\left(6,11^{\circ}\right)$, probably concurrent to its labial component retraction that followed the upper incisors retraction. Concerning its nasal component, the growth forward and downward contributed for this increase not being greater. So, the changes that occured in both anatomical components (labial and nasal) of ANL measurement, brought about in the whole angle a clockwise rotation. Concerning the upper lip, it showed a thickening in both the vermellion border as well as at superior labial sulcus, not being possible to identify its real relation with growth and/or upper incisors retraction. When the variables were analysed concerning the sex, in males the ANL measurement showed a smaller increase $\left(5,2^{\circ}\right)$, as a result of a greater nasal growth forward and downward, further on a smaller labial retraction which may have been compensated by a greater upper lip thickening. In females, the ANL measurement showed a greater increase $\left(7,20^{\circ}\right)$, with a smaller effect of the nasal growth and a greater labial retraction, which presumably occurred as a result of an insignificant increase at upper lip thickness.
\end{abstract}

Key words: Nasolabial angle. Upper lip. Extractions treatment. 


\section{REFERÊNCIAS}

1. ABDEL KADER, H. M. Vertical lip height and dental height changes in relation to the reduction of overjet and overbite in class II, division 1 malocclusions. Am J Orthod, St. Louis, v. 84, no. 3, p. 260-263, Sept. 1983.

2. ANDERSON, J. P.; JOONDEPH, D. R.; TURPIN, D. L. A cephalometric study of profile changes in orthodontically treated cases ten years out of retention. Angle Orthod, Appleton, v. 43, no. 3, p. 324-336, July 1973.

3. ARNETT, G. W.; BERGMAN, R. T. Facial keys to orthodontic diagnosis and treatment planning. Part I. Am J Orthod Dentofacial Orthop, St. Louis, v. 103, no. 4, p. 299-312, Apr. 1993.

4. ASSUNÇÃO, Z. L. V. et al. Incisor retraction and profile changes in adult patients. Int J Adult Orthodon Orthognath Surg, Lombard, v. 9, no. 1, p. 31-36, 1994.

5. ATTARZADEH, F.; ADENWALLA, S. T. Soft tissue profile changes concurrent with the orthodontic treatment. Int J Orthod, Milwaukee, v. 28, no. 1-2, p. 9-16, Spring/Summer. 1990.

6. BATTAGEL, J. M. Profile changes in class II, division 1 malocclusions: a comparision of the effects of Edgewise and Frankel appliance therapy. Eur J Orthod, London, v. 11, no. 3, p. 243253, Mar. 1989.

7. BLOOM, L. A. Perioral profile changes in orthodontic treatment. Am J Orthod, St Louis, v. 47, no. 5, p. 371-379, May 1961.

8. BRANOFF, R. S. A roentgenographic cephalometric study of changes in the soft tissue profile related to orthodontic treatment. Am J Orthod, St. Louis, v. 60, no. 3, p. 305, Sept. 1971. (Abstracts)

9. BRAVO, L. A. Soft tissue facial profile changes after orthodontic treatment with four premolars extracted. Angle Orthod, Appleton, v. 64, no. 1, p. 31-42, 1994

10. BUCHIN, I. D. An appraisal of the effect of the Edgewise arch appliance in modifying the dentofacial profile. Am J Orthod, St. Louis, v. 43, no. 11, p. 801-818, Nov. 1957.

11. BURSTONE, C. J. The integumental profile. Am J Orthod, St. Louis, v. 44, no.1, p. 1-25, Jan. 1958

12. BURSTONE, C. J. Integumental contour and extension patterns. Angle Orthod., Appleton, v. 29, n. 2, p. 93-104, Apr. 1959

13. BURSTONE, C. J. Lip posture and its significance in treatment planning. Am J Orthod, St. Louis, v. 53, no. 4, p. 262-284, Apr. 1967.

14. CHIMENTI, C. et al. Profile modifications induced by orthodontic forces studied by an analysis of the nasolabial angle. Minerva - Stomatol, Turim, v. 43, no. 12, p. 585-590, Dec. 1994.

15. CUMMINS, D. M.; BISHARA, S. E.; JAKOBSEN, J. R. A computer assisted photogrammetric analysis of soft tissue changes after orthodontic treatment. Part II : Results. Am J Orthod Dentofacial Orthop, St. Louis, v. 108, no. 1, p. 38-47, July 1995.

16. DROBOCKY, O. B.; SMITH, R. J. Changes in facial profile during orthodontic treatment with extraction of four first premolars. Am J Orthod Dentofacial Orthop, St. Louis, v. 95, no. 3, p. 220-230, Mar. 1989

17. ELIAS, A. C. The importance of the nasolabial angle in the diagnosis and treatment of malocclusions. Int J Orthod, Milwaukee, v. 18, no. 2, p. 7-12, June 1980.

18. FINNOY, J. P.; WISTH, P. J.; BOE, O. E. Changes in soft tissue profile during and after orthodontic treatment. Eur J Orthod, Oxford, v. 9, no. 1, p. 68-78, Feb. 1987.

19. FITZGERALD, J. P.; NANDA, R. S.; CURRIER, G. F. An evaluation of the nasolabial angle and the relative inclinations of the nose and upper lip. Am J Orthod Dentofacial Orthop, St. Louis, v. 102 , no. 4, p. 328-333, Oct. 1992

20. GARNER, L. D. Soft tissue changes concurrent with orthodontic tooth movement. Am J Orthod, St. Louis, v. 66, no. 4, p. 367377, Oct. 1974.

21. GRIEVE, G. W. Anatomical and clinical problems involved where extraction is indicated in orthodontic treatment. Am J Orthod, St. Louis, v. 30, p. 437-443, July/Dec. 1944.

22. HAMBLETON, R. S. The soft tissue covering of the skeletal face as related to orthodontic problems. Am J Orthod, St. Louis, v. 50, no. 6, p. 405-420, June 1964.
23. HEATH, J. R. The nasolabial angle in diagnosis. Austr Orthod J Melbourne, v. 12, no. 1, p. 55, Mar. 1991.

24. HERSHEY, H. G. Incisor tooth retraction and subsequent profile change in postadolescent female patients. Am J Orthod St. Louis, v. 61, no. 1, p. 45-54, Jan. 1972.

25. HERZBERG, B. L. Facial esthetics in relation to orthodontic treatment. Angle Orthod, Appleton, v. 22, no. 1, p. 3-22, Jan. 1952

26. HOLDAWAY, R. A. Changes in relationship of points $A$ and $B$ during orthodontic treatment. Am J Orthod, St. Louis, v. 42, no. 3, p. 176-193, Mar. 1956

27. HOLDAWAY, R. A. A soft tissue cephalometric analysis and its use in orthodontic treatment planning. Part I. Am J Orthod, St. Louis, v. 84, no. 1, p. 1-28, July 1983.

28. HORN, A. J.; JEGOU, I. A look at soft tissue modifications. Rev Tweed Found, Tucson, p. 43-57, Apr. 1988

29. HUGGINS, D. G.; McBRIDE, L. J. The influence of the upper incisor position on soft tissue facial profile. Br J Orthod, Edinburgh, v. 2 , no. 3, p. 141-146, July 1975

30. JACKSON, D. Lip positions and incisor relationships. Br Dent J, London, v. 112, no. 4, p. 147-159, Feb. 1962

31. JACOBS, J. D. Vertical lip changes from maxillary incisor retraction. Am J Orthod, St. Louis, v. 74, no. 4, p. 396-404, Oct. 1978.

32. KING, E. W. Variations in profile change and their significance in timing treatment. Angle Orthod, Appleton, v. 30, no. 3, p. 141-153, July 1960.

33. KOCH, R.; GONZALES, A.; WITT, E. Profile and soft tissue changes during and after orthodontic treatment. Eur J Orthod, Oxford, v. 1, no. 3, p. 193-200, Mar. 1979.

34. KROGMAN, W. M.; SASSOUNI, V. Syllabus in roentgenographic cephalometry. Philadelphia: Philadelphia center for research in child growth, 1957. p. 45-103.

35. LEW, K. Profile changes following orthodontic treatment of bimaxillary protusion in adults with The Begg appliance. Eur J Orthod, London, v. 11, no. 4, p. 375-381, Nov. 1989.

36. LIEBERMAN, M. A.; GAZIT, E. Facial profile as affected by extraction or nonextraction decisions. Quintessence Int, Chicago, v. 13 , no. 4, p. 447-454, Apr. 1982

37. LO, F. D.; HUNTER, W. S. Changes in nasolabial angle related to maxillary incisor retraction. Am J Orthod, St. Louis, v. 82, no. 5 , p. 384-391, Nov. 1982.

38. LOOI, L. K.; MILLS, J. R. E. The effect of two contrasting forms of orthodontic treatment on the facial profile. Am J Orthod, St. Louis, v. 89, no. 6, p. 507-517, Jun. 1986.

39. MAGNI, F.; DI BLASIO, A. Cephalometric evaluation of the nasolabial angle. Mondo Orthod, Milano, v. 15, no. 2, p. 139-144 1990

40. MATSUNAGA, R. A cephalometric appraisal of hard and soft tissue changes in class II, division 1 malocclusions following orthodontic therapy. Am J Orthod, St. Louis, v. 49, no. 11, p. 863 , Nov. 1963. Abstracts.

41. McNULTY, E. C.; LEAR, C. S. C.; MOORREES, C. F. A. Variability in lip adaptation to changes in incisor position. J Dent Res Boston, v. 47, no. 4, p. 537-547, Aug. 1968

42. NEGER, M. A quantitative method for the evaluation of the soft tissue facial profile. Am J Orthod, St Louis, v. 45, no. 10, p. 738 751, Oct. 1959

43. OLIVER, B. M. The influence of lip thickness and strain on upper lip response to incisor retraction. Am J Orthod, St. Louis, v. 82 no. 2, p. 141-149, Aug. 1982

44. PHELPS, A. E. Facial esthetics and the Tweed technique. Rev Tweed Found, Tucson, p. 28-38, Apr. 1988

45. REZENDE, M. E. B.; MARTINS, J. E. S. Avaliação do comportamento do lábio superior em casos de classe II, $1^{\text {a }}$ divisão, tratados com aparelho Edgewise. Ortodontia, São Paulo, v. 17, n. 1 - 3, p. 29-42, jan./dez. 1984.

46. RICKETTS, R. M. Planning treatment on the basis of the facia pattern and an estimate of its growth. Angle Orthod, Appleton, v. 27, no. 1, p. 14-37, Jan. 1957.

47. RICKETTS, R. M. Esthetics, environment, and the law of lip relation. Am J Orthod, St. Louis, v. 54, no. 4, p. 272-289, Apr. 1968 
48. ROBISON, J. M. RINCHUSE, D. J.: ZULLO, T.G. Relationship of skeletal pattern and nasal form. Am J Orthod, St. Louis, v. 89, no. 6, p. 499-506, June 1986

49. ROOS, N. Soft tissue profile changes in class II treatment. Am J Orthod, St. Louis, v. 72, no. 2, p. 165-175, Aug. 1977.

50. RUDEE, D. A. Proportional profile changes concurrent with orthodontic therapy. Am J Orthod, St. Louis; v. 50, no. 6, p. 421434, June 1964.

51. SAIN, J. Changes in the integumental profile concomitant with orthodontic treatment. Am J Orthod, St. Louis, v. 48, no. 8 p. 624-625, Apr. 1962. Abstracts.

52. SCAVONE JR, $H$. FREITAS, M R - HENRIQUES, J. F C Estudo cefalométrico longitudinal das alterações no perfil facial tegumentar, posteriores ao tratamento ortodôntico, em jovens leucodermas do sexo masculino. Ortodontia, São Paulo, v. 26 n. 1, p. 38-57, jan.abr. 1993

53. STONER, M. M. et al. A cephalometric evaluation of 57 cases treated by Dr. C. H. Tweed. Angle Orthod, Appleton, v. 26, no. 2, p. 68-98, 1956.

54. STROMBONI, Y. Facial aesthetics in orthodontic treatment with and without extractions. Eur J Orthod, London, v. 1, no. 3, p. 201-206, Mar. 1979
55. SUBTELNY, J. D.: ROCHESTER, M. S. A longitudinal study of soft tissue facial structures and their profile characteristics, defined in relation to underlying skeletal structures. Am J Orthod, St. Louis, v. 45, no. 7, p. 481-507, July 1959.

56. SUBTELNY, J. D. The soft tissue profile, growth and treatment changes. Angle Orthod, Appleton, v. 31, no. 2, p. 105-122, Apr. 1961.

57. TALASS, M. F.; TALASS, L.; BAKER, R. C. Soft tissue profile changes resulting from retraction of maxillary incisors. Am J Orthod Dentofacial Orthop, St. Louis, v. 91, no. 5, May 1987.

58. TWEED, C. H. Indications for the extraction of teeth in orthodontic procedure. Am J Orthod, St. Louis, v. 30, p. 405-428, July/Dec. 1944

59. WALDMAN, B. H. Change in lip contour with maxillary incisor retraction. Angle Orthod, Appleton, v. 52, no. 2, p. 129-134, Apr. 1982.

60. WISTH. P. J. Soft tissue response to upper incisor retraction in boys. Br J Orthod, Edinburgh, v. 1, no. 5, p. 199-204, Mar. 1974.

61. YOUNG, T. M.; SMITH, R. J. Effects of orthodontics on the facial profile : A comparision of changes during nonextraction and four premolar extraction treatment. Am J Orthod Dentofacial Orthop, St. Louis. v. 103, no. 5, p. 452-463, May 1993.
Endereço para correspondência

Fabio Rogerio Torres Maria

Av. Rio Grande do Norte, 1991

Paranavaí/PR

CEP: 87.705-010

E-mail: frtm@uol.com.br / ortolife.com@uol.com.br 